\title{
CARACTERÍSTICAS EPIDEMIOLÓGICAS DO SUICÍDIO NA MACRORREGIÃO SUL DO ESTADO DE SANTA CATARINA
}

Lucas Corrêa Preis Acadêmico do Curso de Enfermagem, Centro Universitário Barriga Verde, lucaspreis@yahoo.com

Greice Lessa

Doutoranda em Enfermagem, Universidade Federal de Santa Catarina, greicelessa@hotmail.com Giseli Orben

Acadêmica do Curso de Enfermagem, Centro Universitário Barriga Verde, gisele_riof@hotmail.com

Jaqueline Caetano

Acadêmica do Curso de Enfermagem, Centro Universitário Barriga Verde, jaqueline-gr@hotmail.com Kassiane Dutra Acadêmica do Curso de Enfermagem, Centro Universitário Barriga Verde, kassidutra@hotmail.com Mislene Beza Gordo Sarzana Acadêmica do Curso de Enfermagem, Centro Universitário Barriga Verde, misbn@hotmail.com

\section{RESUMO}

O suicídio, conhecido pelo ato intencional de morte, na maioria das vezes, é associado a casos de transtornos mentais ou psicológicos, como 
a depressão, transtorno bipolar, esquizofrenia e abuso de drogas, bem como impossibilidades do indivíduo de identificar alternativas viáveis para a solução de seus conflitos, optando, assim, pela morte como resposta de fuga da situação estressante. Ao longo dos anos, o suicídio tem se tornado cada vez mais frequente, considerando-se um problema grave de saúde pública, trazendo consigo importantes gastos aos serviços de saúde, além da perda de capital humano (OLIVEIRA; FILHO; FEITOSA, 2012). Assim, o trabalho objetiva apresentar as características epidemiológicas das mortes por suicídio na macrorregião sul de Santa Catarina, entre os anos de 2004 e 2013, bem como descrever a principal forma utilizada para a concretização do ato de suicídio na região e no período estudado. A presente pesquisa foi um estudo descritivo, retrospectivo e não probabilístico, realizado com dados secundários extraídos do sistema TABNET, no item mortalidade, publicados pelo departamento de informática do Sistema Único de Saúde do Brasil (DATASUS) e disponíveis no endereço eletrônico do Ministério da Saúde, no período de 2004 a 2013, utilizando todas as causas de morte. Destaca-se que os dados são de domínio público, com acesso disponível pela rede mundial de computadores. Foi selecionada intencionalmente a macrorregião sul, composta por três regióes de saúde (Laguna, Carbonífera e Extremo Sul Catarinense), localizadas no sul de Santa Catarina, abrangendo 43 municípios e com uma população de 921.661 habitantes (BRASIL, 2012). Foram coletados dados do sistema informatizado TABNET, no período de 05 de novembro a 10 de dezembro de 2015 , relativos às seguintes variáveis: óbitos por cidade de residência, ano do óbito, sexo, faixa etária, estado civil, cor/ raça, escolaridade, local da ocorrência e causa da morte. Os dados foram consolidados em uma planilha do programa Excel, versão 2010. A partir da coleta de dados, chegou-se a 50.683 mortes, entre os anos de 2004 a 2013, na macrorregião sul. Dos 50.683 óbitos, 716 tinham como causa da morte o suicídio, sendo 535 do sexo masculino e 181 do sexo feminino. Em relação à faixa etária, a maior concentração de óbitos decorrentes de suicídio foi de pessoas com idade entre 20 e 49 anos (com 450 mortes no período), seguida de pessoas com idade entre 50 e 79 anos (com 228 mortes), 10 e 20 anos 
(com 25 óbitos) e com idade acima dos 80 anos, que representou a menor incidência, com 13 óbitos. Em relação ao estado civil, a maior parte da população residente na macrorregiáo sul que cometeu suicídio era casada, com 254 casos, seguida da população solteira (com 228 óbitos). A cor/raça que representou a maior quantidade de óbitos por suicídio na regiáo foi a branca, com 650 óbitos, seguida das raças preta e parda, com 15 casos cada uma. No que diz respeito ao local da ocorrência do suicídio, a maior parte da população suicidou-se em seu próprio domicílio, representando 449 casos. Em hospitais ou outros estabelecimentos de saúde, houve 102 casos. Além disso, existiram 40 casos de suicídio em via pública. Em relação à escolaridade da população que cometeu suicídio, do total de 716 casos, 418 óbitos tinham entre 1 e 11 anos de estudo; 45 óbitos tinham 12 anos e mais; enquanto 26 não tinham nenhuma instrução. No que diz respeito aos métodos mais empregados para concretização do suicídio, a lesão por enforcamento, estrangulamento e sufocação representou a maior incidência, com 523 casos, seguida da lesão por disparo de arma de fogo, com 49 óbitos. A intoxicação por drogas anticonvulsivantes, sedativos, hipnóticos, antiparkinsonianos e psicotrópicos não classificados em outra parte e a intoxicação com pesticidas representaram 21 casos cada. Ao analisar dados de mortalidade por suicídio, deve-se considerar a dificuldade de apresentar a real quantidade de óbitos por suicídios, em função da solicitação de familiares quanto à mudança das causas básicas das mortes ou da dificuldade de delimitação do caso entre suicídio, acidente ou homicídio. Apesar disso, ressalta-se a grande importância e os inúmeros benefícios trazidos por estudos que apresentam as características epidemiológicas, bem como o perfil da população que comete suicídio em determinadas regióes, visando à implantação ou ao direcionamento de ações de saúde para a supressão dos índices crescentes de mortes por lesóes autoprovocadas (SANTOS, 2013). Os achados na macrorregião sul confirmam estudos anteriores de uma maior mortalidade masculina. A diferença dos índices entre o sexo está no comportamento suicida, explicando-se na forma de que as mulheres tendem a cometer mais tentativas de suicídio, enquanto os homens, o suicídio, demonstrando, assim, maior intenção de 
morte, bem como utilização de meios mais letais, como enforcamento, utilização de arma de fogo ou precipitação de elevadas alturas. Nesta mesma linha, está relacionada à faixa etária. Enquanto a maior parte dos suicídios concretizados está ligada à população com maior idade, as tentativas de suicídio estão ligadas à população jovem (SOUZA et al., 2011). O local da ocorrência, bem como o método utilizado para concretização do ato de suicídio, foi semelhante a outros estudos já publicados e, geralmente, estão associados a fatores de disponibilidade e acesso aos meios para se suicidar. $\mathrm{Na}$ região estudada, bem como em contexto nacional, o local e o método definido para se suicidar foram domicílio e enforcamento, respectivamente. Estudos confirmam que o enforcamento está sempre entre a principal escolha para concretização do suicídio, em função de provocar lesões fatais mais rapidamente e, na maioria das vezes, sem tempo para chamar socorro médico ou encaminhá-los a hospitais (FALCÃO; OLIVEIRA, 2015). Com relação ao estado civil, a literatura aponta que a maior parte dos suicídios são decorrentes de pessoas solteiras, viúvas ou divorciadas, pois é a população classificada com a maior vulnerabilidade a cometer suicídio. No presente estudo, observou-se que a maior parte dos suicídios foi de pessoas com estado civil casado, contrariando dados obtidos em estudos anteriores. Geralmente estes casos são isolados, e a maior quantidade de suicídio de pessoas casadas pode ter sido casual, refletir um determinado período ou estar associado a fatores de ordem financeira (VIDAL; GONTIJO; LIMA, 2013). A partir do estudo, percebeu-se que a temática do suicídio é extremamente ampla e um grave problema a ser enfrentado pela saúde pública. Os resultados encontrados na região estudada se assemelham parcialmente a outros estudos em diferentes regióes do Brasil, especialmente quanto ao sexo, meios utilizados para o suicídio e local da ocorrência. Os suicídios aconteceram principalmente entre a população masculina, de 20 e 49 anos e solteiros, escolhendo o enforcamento e o domicílio para consumação do ato. Sugere-se, então, a capacitação das equipes de saúde da família, quanto à identificação das pessoas e grupos vulneráveis ao suicídio, a fim de orientar as famílias que convivem com tais grupos, visando à vigilância e à prevenção dos eventos, 
bem como à realização e publicação de novos estudos que tratem das características epidemiológicas do suicídio, buscando conhecer o panorama envolvido nas regióes estudadas, possibilitando, assim, desenvolver novas açóes de saúde ou reformular e ampliar as açóes pré-existentes.

Palavras-chave: Suicídio; Epidemiologia; Sistemas de Informação.

\section{REFERÊNCIAS}

BRASIL. Ministério da Saúde. Populaçáo Residente em Santa Catarina. 2012. Disponível em: <http://tabnet.datasus.gov.br/cgi/tabcgi.exe?ibge/cnv/popsc. def>. Acesso em: 28 jan. 2016.

FALCÃO, C. M.; OlIVEIRA, B. K. F. Perfil epidemiológico de mortes por suicídio no município de Coari, entre os anos de 2010 e 2013. Revista LEVS, Marília, v.15, n.1, p.44-55, 2015.

OLIVEIRA, M. I. V.; BEZERRA FILHO, J. G.; FEITOSAC, R. F. G. Estudo epidemiológico da mortalidade por suicídio no estado do Ceará, no período 1997-2007. Revista Baiana de Saúde Pública, Salvador, v.36, n.1, p.159-173, 2012.

SANTOS, S. A. Substâncias tóxicas e tentativas e suicídios: considerações sobre acesso e medidas restritivas. Caderno de Saúde Coletiva, Rio de Janeiro, v.21, n.1, p.53-61, 2013.

SOUZA, V. S. et al. Tentativas de suicídio e mortalidade por suicídio em um município no interior da Bahia. Jornal Brasileiro de Psiquiatria, Salvador, v.60, n.4, p.294-300, 2011.

VIDAL, C. E. L.; GONTIJO, E. C. D. M.; LIMA, L. A. Tentativas de suicídio: fatores prognósticos e estimativa do excesso de mortalidade. Cadernos de Saúde Pública, Rio de Janeiro, v.29, n.1, p.175-187, 2013. 